Working paper

\section{Sierra Leone's}

National

Export

Strategy

Implementation

Issues and

Recommendations

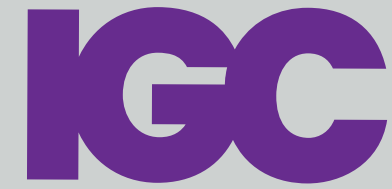

International

Growth Centre

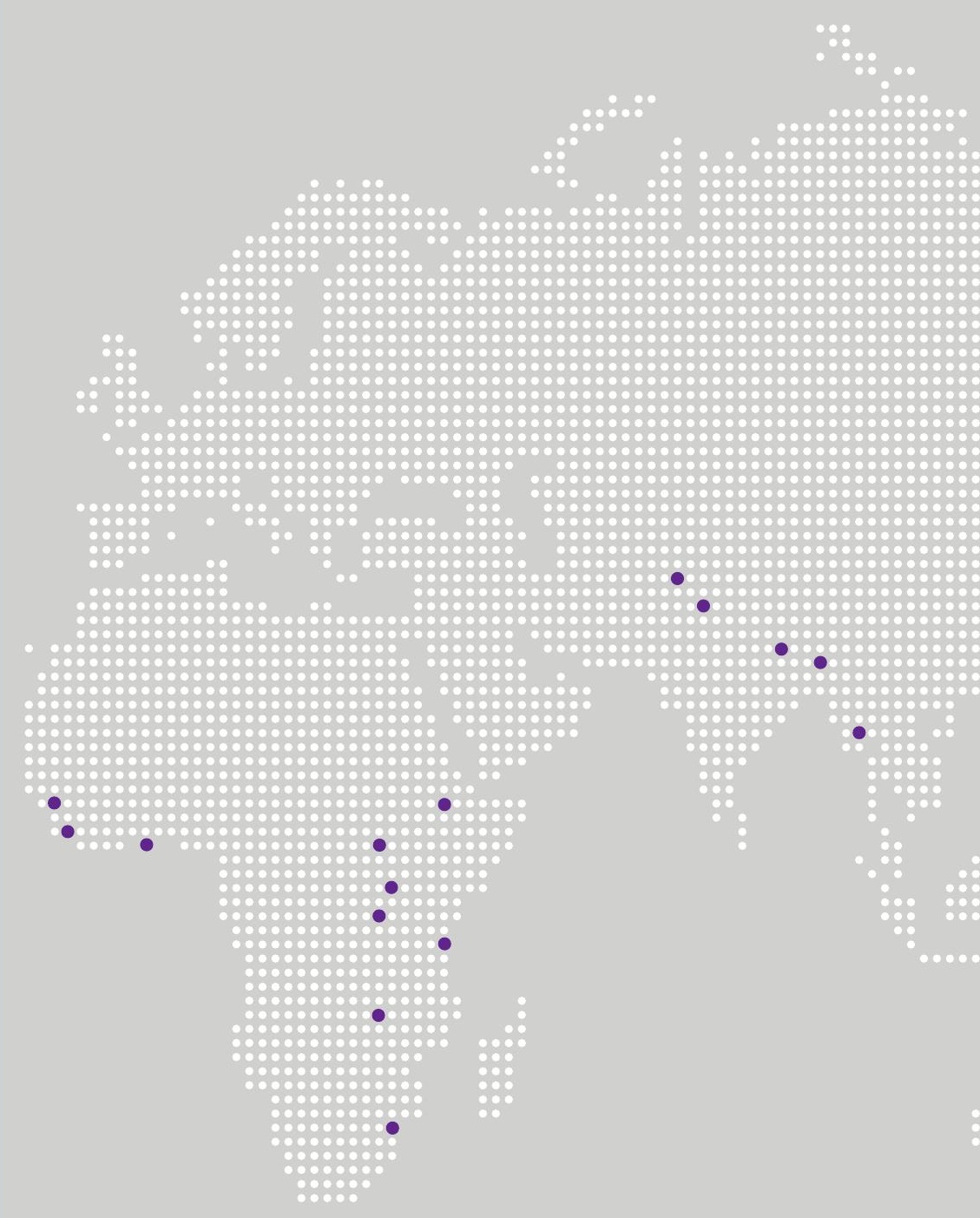

Marianna Belloc Michele Di Maio

August 2011

When citing this paper, please use the title and the following reference number:

F-39012-SLE-1 


\title{
Sierra Leone's National Export Strategy: Implementation Issues and Recommendations
}

\author{
Marianna Belloc, University of Rome - Sapienza, Italy \\ Michele Di Maio, University of Naples - Parthenope, Italy
}

August 2011

This report concentrates on the development of an overall strategy for promoting export growth in Sierra Leone. This follows a specific request from the Sierra Leone authorities, in the context of the International Growth Centre (IGC) Country Programme of Sierra Leone. This report was carried out through a fact-finding mission in May 2011. The mission received the full cooperation of the relevant ministries and agencies, in particular the Ministry of Trade and Industry and the Sierra Leone Investment and Export Promotion Agency (SLIEPA). The mission also benefitted from the views of the private sector, foreign and domestic, bilateral donors and international development agencies. A preliminary version of this report was discussed at a meeting at SLIEPA headquarters in Freetown on May 24, 2011.

\section{Acknowedgments}

We would like to thank the IGC In-Country Economists Rebecca Simson and Tom Coward, the IGC In-Country Senior Associate, Claudius Thomas, and the IGC Country Director, Omotunde E.G. Johnson, for the very useful discussions we had during our visit. We also would like to thank all the people we had the opportunity to meet and interview during our stay in Sierra Leone for their kind cooperation. All errors or misinterpretations are obviously our own. 


\section{1) Overview}

Sierra Leone is one of the least developed countries in the world and has suffered from serious losses in terms of human and physical resources due to the ten-year rebel war, which ended in 2001. In recent years the government has made a visible effort to give a new start to the economy. A number of programs and policies have been designed to address different weaknesses that characterize the economy. Interestingly, these attempts have not only seen an increasing participation of the local private sector but also of NGOs, international donors and regional and sub-regional institutions.

In particular, there is a widely shared view on the importance of increasing export. This follows the recognition of the potential role of export as an engine of growth especially for a country, such as Sierra Leone, with a small domestic market. However, the economic condition of Sierra Leone, especially as far as the export sector is concerned, is challenging.

According to the most recent data from the WTO (International Trade Center, 2011), in 2009 the balance of payments registers a significant external trade deficit. The net trade index (export import)/(export + import) in 2009 was equal to $-33 \%$. The three most exported products are Diamonds -HS7102 ${ }^{1}-(22.74 \%$ of total export), Titanium ores and concentrates -HS2614(11.75\%) and Cocoa beans, whole or broken, raw or roasted -HS1801- (8.48\%), while the most imported are Electrical and electronic equipment -HS8500- (15.17\% of total import), Machinery and parts of machinery -HS8400- (9.61\%) and Petroleum oils, not crude -HS2710- (8.55\%). Surprisingly given the agrarian nature of the economy, the trade balance for processed food products is negative (in 2009 the share in national export was equal to $2 \%$ and that of national imports to 14\%). These rough figures illustrates why the government of Sierra Leone is strongly motivated to increase net export: as the country's products are currently uncompetitive in the international markets, and it is highly dependent on foreign products in a number of important sectors. Such a situation generates two main problems: the first is a balance of payments problem, causing a persistent situation of deep external debt, meaning the country is continuously forced to borrow resources from the rest of the world. The second concerns the composition of domestic exports which are highly dependent on mineral extraction and cocoa production, so the specialization structure is based on natural resource exploitation with almost no value addition.

\footnotetext{
${ }^{1}$ We refer to either two-digit or four-digit Harmonized System classification.
} 
From this it follows that the government's concerns regard both the intensive and the extensive margins of exports. The former refers to the depth or the intensity of the country's trade (how much the country exports), whilst the latter relates to the diversification of the export portfolio (how many different products and services are exported by the country). The aim of the government is thus not only to increase the value and volume of products that are currently exported but also to shift the specialization structure from traditional products (mining, cocoa) to non-traditional ones (fisheries, agricultural processed food, mango, pineapple). Although carefully evaluating the experience by the various countries and assessing the effectiveness of the policies is crucial to provide governments with guidelines to identify the best practices (see Belloc and Di Maio, 2011), reviewing successes and failures of the strategies implemented elsewhere can only provide some hints, starting from which each country should find its own way. This is true in general (each country faces its own specificities, has its own potentialities and threats, its own institutions, and so on), but it is especially true in a rapidly changing context such as the one Sierra Leone now faces. New challenging issues are arising; new competitors and players are taking the stage in the international arena (China, India, Brazil) and old players are increasing their power (EU); the rules of the game are changing and becoming more and more complex (WTO rules, international standards compliance, rules of origin); the regional integration process is rapidly going ahead and modifying the balance of power within the Economic Community Of West African States (ECOWAS); substantial economic transformation is taking place (demand and technology).

\section{2) The National Export Strategy}

\section{1) Structure of the NES}

The National Export Strategy (NES) is a policy document for the period 2010-2015 aimed at evaluating and discussing potentialities and constraints to export. The overall objectives of the NES are to boost the competitiveness of Sierra Leone and enhance its export performance, whilst strategic objectives consist of increasing productivity, enhancing value addition, diversifying export and improving human and financial capacity of the stakeholders. The ultimate goal is to increase income and standards of living. The vision set out in the NES is "transforming Sierra Leone into a flourishing country through a globally competitive export driven economy" (Government of Sierra Leone,, 2010: 13). 
The NES is one of the instruments to achieve the objectives put forward by the Agenda for Change - the Second Poverty Reduction Strategy Paper and is complemented by other existing initiatives such as the National Sustainable Agricultural Development Plan (NSADP), the Fisheries Strategic Plan, the Tourism Master Plan and the Minerals Policy.

The document has been produced by a team of experts comprising four institutions: the Ministry of Trade and Industry, SLIEPA, the Sierra Leone Business Forum and the Sierra Leone Exporters Association. During the scoping visit we have personally met some of them, as we will discuss in the next sections. The document is organized in three parts, briefly described below.

The first part is devoted to the analysis and evaluation of the current situation faced by Sierra Leone. In particular, both demand side and supply side issues are explored. As for the demand side, a brief description of the position of Sierra Leone within the international trade arena is presented with special regard to regional agreements, such as the ECOWAS and the African Growth Opportunity Act (AGOA), to the relationship with the EU and to the South-South cooperation. As for the supply side, the following issues are considered: productivity, capacity, standards, and rules of origin.

The second part of the NES focuses on the selection of the priority sectors according to specific criteria. In particular seven criteria are identified: current contribution to exports, contribution to GDP, potential to create local employment, capacity to improving livelihoods, potential for export, potential for diversification, and potential for alleviating gender issues. Based on these criteria four priority sectors are selected: the agricultural sector, the fisheries sector, the mining sector, and the tourism sector. Two specific criteria are suggested to be reapplied in order to identify subsectors; they are: potential for export and potential for diversification. The final outcome was selecting the agricultural sector as the only one, among the four priority sectors, able to meet the two specific criteria. Within the agricultural sector the following subsectors are highlighted: coffee, cocoa, oil palm, cashew, rice, cassava, ginger, chili and sugar.

For each of the four priority sectors and for each subsector, an analysis is conducted comprising the sector overview, the strengths, weaknesses, opportunities and threats (SWOT), and the strategic vision (issues and objectives). Furthermore, for each subsector a four-year strategy is set, consisting of identified strategic objectives, strategy, activities, responsible partners (either public or private), and the cost over the four years. 
The second part of the NES considers cross cutting issues, that is a number of issues that concern all the sectors and subsectors identified in the previous part of the document. These are: trade finance, quality management, trade facilitation, export competence development, export packaging, trade information services. For each of them strategic issues and objectives, including cost analysis, are described.

Finally, the third part concerns the financing and the implementation strategy. The latter is the most interesting for the scope of this report. Implementation will be carried out by three entities; the National Steering Committee, four Sector Working Groups and four Sector Task Forces. The first of these will be established as a private-public partnership and chaired by the Ministry of Trade and Industry; it will have the highest political representation and will perform strategic direction and coordination duties. The NES report also clarifies that government ministries, departments and agencies will be members of the National Steering Committee with implementation duties. Sector Working Groups will be established for Agriculture and Fisheries, Tourism, Minerals and a Cross-Cutting Sector, with Sector Task Forces for Agriculture, Fisheries, Cross Cutting 1 and 2, which will coordinate and monitor implementation, evaluate and update strategies, and develop financial plans in each sector. Finally, SLIEPA will offer secretariat, administrative and support services, connecting the National Steering Committee with the Sector Working Groups and Tasks Forces and enhancing cooperation between private and public parties.

\section{2) Preliminary comments on the NES}

As stated above, the NES pursues ambitious objectives, such as boosting competitiveness and enhancing export performance of Sierra Leone, in the view of increasing income and standards of living.

From this it turns out clear that expectations from the NES implementation are considerable. The fact that the strategy is expected to be very far-reaching should be considered with prudence. Even the optimal designed export promotion strategy may fall short of such varied and broad expectations. A too broad and unfocused strategy may be counterproductive in terms of political support to the policy when its outcomes will be evaluated. Boosting exports cannot be an end in itself: a careful strategy has to be designed to identify how the ultimate welfare benefits from that achievement will be reaped. Hence, the objective of Sierra Leone is to craft an export promotion strategy (design and implementation) to boost its economic growth and development and, 
consequently, the NES and its implementation strategy must be tailored to achieve this ultimate result. This paper is a contribution to this effort. First, a distinction between far-reaching desiderata and feasible medium term objectives is crucial: the effects of inappropriate policies are not always reversible; therefore policy objectives must be verifiable on the way and achievements must be measurable. This cannot be done unless goals are well-defined and clearly stated on a time schedule. From this it follows that a more neat selection among the desiderata would enhance the pragmatism of the NES. Second, the NES should be clearer on the distinction between short run and long run objectives. This is a serious concern since, as we argue below, one of the key to the success of any export promotion strategy is the sequencing of interventions and the coherence between short run and long run policies and objectives. Third, as regards the implementation of the NES, which is discussed at the end of the document, a clear identification of the entities responsible for the implementation of the strategy is useful. In the current version of the NES document, the duties of the three involved entities (National Steering Committee, Sector Working Groups and Sector Task Forces) are not clearly spelled out and some confusion exists between coordination and implementation.

\section{3) The scoping visit}

The meetings and interviews with public officials and the private sector were designed to gather as much information as possible to understand the current economic situation of Sierra Leone, to recognize the major challenges the country is currently facing and will have to deal with in the future concerning export growth, and to identify the key opportunities to be exploited. The ultimate goal was to advise on the design and the implementation of an export promotion policy in the country. The meetings were arranged in the sectors that have been identified by the NES as key sectors for their potential in export activities, namely agriculture, fisheries, mining and tourism. Specifically, the interviews focused on investigating the main obstacles to exporting in Sierra Leone.

The entities that have been interviewed are reported below, distinguishing between private and public sector.

- Public sector: SLIEPA; SPU; Ministries of Trade and Industry, of Agriculture, Forestry and Food Security, of Fisheries, of Mineral Resources, and of Tourism and Culture; the Standard Bureau; Bank of Sierra Leone; Bureau of Tourism; Resident Minister (Northern 
Province); Growth Centre (Makeni); Port Authorities; and Commodity Market Monitoring Unit (CMMU).

- Private sector: Bennimix, Addax, First Step SEZ (African Felix Juice), Sierra Fisheries, Guoji SEZ, Franco's restaurant (Freetown), Milla company, Cotton Tree Foundation, Sierra Leone Exporters Association, and Chamber of Commerce, Industry and Agriculture.

Clearly the sample of the private producers is not representative of the domestic production system. Since the main goal of the meetings was to understand obstacles and opportunities to exporting, the choice of the entrepreneurs to interview was, indeed, mainly dictated by the need to meet those companies that are currently exporting or that have potentialities to become exporters in the near future.

At the beginning of any meeting the team was introduced by the Resident Senior Associate, in order to explain the reason for the meeting and the aim of the project. The interviews were then conducted focusing on obstacles and opportunities to exporting, but they changed somewhat depending on the meeting. Since an important aim of the Sierra Leone export promotion strategy consists in capturing as much of the value chain as possible, the interviews with private actors were also concerned with the main potentialities that the various entrepreneurs deem important to achieve such a goal. The interviews with public officials also concerned what the various government ministries, departments and agencies are doing or intend to do to achieve the proposed objectives.

This scoping visit is part of the more general novel approach to policy design that suggests the need of a closer interaction between the public and the private sector. The scoping visit in fact also served the aim of making the ministries, public officials and the private sector more aware of the multiple aspects of the NES. This is clearly a different method with respect to the 'old fashioned' top-down approach to industrial policy or to the dirigist policies of the Developmental State period.

\section{4) Main findings}

The consultations have resulted in recognizing the existence of still binding capacity constraints. The general picture that emerged from the meetings is that of a very complicated situation where different constraints are binding at different stages of the value chain and involve both the demand 
and the supply side. In what follows we will discuss them in turn, always keeping in mind that each of them is strictly related with all the others and that often singling out the main bottleneck is a difficult task. The key identified issues are:

- capabilities (both of the private sector and the government);

- physical infrastructure;

- quality and standards;

- financial services;

- land tenure system;

- private sector awareness about opportunities.

Finally, during the interviews the intention was also trying to understand the quality of the business environment and the ease of doing business as perceived by the private sector. Indeed the Doing Business project by the World Bank (2011) (see section 4.7) suggests that Sierra Leone is making progress in some indices. The interviews thus also aimed at verifying if the information documented by the World Bank record is confirmed by the stakeholders' perceptions.

\section{1) Improving but still weak capabilities}

In order for export growth and development to take place, fostering cooperation among the different economic actors is important. Any strategy to be implemented requires the direct and interacting involvement of all the interested parties. This is especially true for the export promotion strategy that, to be successful, requires profound changes and interventions in several sectors of the economy and considerable efforts by several actors both in the private and in the public domains.

First, it is crucial that the various levels of the public sector, the national government, the provincial government and the government agencies, coordinate in order to set the key goals, agree on a strategy, identify the responsibilities and check on the results. The interviews revealed insufficient coordination among public authorities. Even when the ministry officials and the representatives of the various public agencies agreed on the objectives to pursue, it was unclear which actor had exactly the responsibility to do what and to achieve which intermediate target. This not only was clear from interviewing the public sector representatives, but also was revealed by the private actors that pointed at the lack of coordination among authorities as one of the key 
obstacles to implement an effective export strategy. Clarifying responsibilities and identifying the areas of intervention of the different ministries and public agencies have been acknowledged as important to endow the private producers and potential exporters with the right signals and a clear understanding of the responsible entities to which they can refer to in the different circumstances.

Second, the public sector should cooperate with private actors who are involved in production and exporting activities. This is crucial for several reasons. Our interviews made it clear that the difficulties faced by the private actors in trying to enhance production and to start or increase export are not fully understood by the public sector. An illuminating example was offered by the land tenure issue that we will discuss below (subsection 4.5). The interview with a private entrepreneur emphasized the necessity to deal with the problem of the lack of guarantees about the use of land in the long run (which was considered crucial for investment). By contrast, an interview with a government official suggested that he did not believe that land was an issue at all. This example hints at a lack of communication between the private and the public sector, or (at least) wrong perception by one of the parties involved.

Limits to government capabilities also relate to the lack of information. One of the elements that have emerged during the interviews with the public authorities is that there is not a functioning and organized system for data collection. Such a system is especially important for mapping the current situation, to obtain a clear picture of where certain policies need to be implemented, accompanied by appropriate policy evaluation. For this to be possible the different agencies and ministries need to know the tasks and responsibilities each actor will assume, in a coordinated effort. The current situation in this kind of framework is worrisome. To the question about whether or not there are firm-level data (that are becoming nowadays available in most of the countries in the world) public officials have answered that there are some data from different sources but the collection process is totally decentralized. For instance, the Ministry of Trade and Industry has the register of firms to evaluate the impact of the Doing Business project; the Ministry of Labor and the National Security has other incomplete data on workers. It was not clear whether or not these two data sources can be merged. Practically firm level data does not really exist. This is an important limitation to the attempt to design and implement any policy, especially one on export promotion.

Cooperation among policy actors and stakeholders, in turn, requires specific capabilities to be in place. These range from knowledge of markets to the awareness of the main challenges and opportunities for exporting, and from a high-quality education to advanced managerial capacity. 
These capabilities are improving in Sierra Leone: the public officials are investing resources in this direction and attempting to get the private sector involved. This was suggested by interviews with public officials (e.g. SLIEPA). The feedbacks from private actors however are mixed. Some producers (e.g. in the processed food sector) highlighted that the connection with SLIEPA was crucial for improving their performance (they had the chance to participate to trade exhibitions to make their product known in the international market, they benefited from mediation with the government to obtain duty drawback concessions, etc). Some other producers, on the contrary, depict a different situation. The Exporter Business Association (a private lobbying association supposed to represent and give voice to the interests of the local exporters), for instance, complains of the lack of support from the government on the one side, and weak responsiveness to its activities from the private sector on the other.

Furthermore, there is a shared view that novel and improved capabilities are needed. In particular Sierra Leone has to deal with rapid and continuous changes that are characterizing the international arena. Among them one can mention the process of regional integration within the ECOWAS, the multilateral negotiation within the WTO, the relation between ECOWAS and the main trading partners, especially the EU, and the other trade agreements such as the AGOA. It is crucial that both the public and the private sector invest in the acquisition and the development of stronger capabilities to be used in the coordination activities. First, the government representatives should align their own capabilities to the new and changing international context. The general impression is that there is still much to do. Second, both the general education system and specific training programs should be crafted and enhanced to provide adequate capabilities for the private sector. A clear example where this effort is necessary is that regarding quality standards (see section 4.3). The private sector does not have the skills and capabilities (sometimes not even the awareness as we will discuss below) to properly enhance the quality of their products in order to improve their profits from production. On the other hand, the Standard Bureau (which is the agency mostly responsible for quality control) has still a small staff but its personnel have been trained in laboratories in Sri Lanka, India, China, etc. However no local specific training program is provided so far by either the Standard Bureau or the University (although this is desirable and currently under consideration by the Standard Bureau). This is most noticeably an issue for the cocoa sector.

Finally, to remove some binding capacity constraints, it is crucial that private producers acquire the capabilities need to organize among themselves in order to manage production at a 
higher level. ${ }^{2}$ Entrepreneurs in the processed food sector suggested that they face important obstacles to increase production stemming from the fact that supply of inputs and intermediate products (for instance rice) is not reliable. Local rice farmers are small-holders generally producing at a self-sufficiency level. The lack of organization and cooperation among them create strong inefficiencies that could be removed by establishing a cooperative of producers able (once the farmers are properly trained) to increase production, exploit economies of scale, share the risk of negative shocks, acquire bargaining power to guarantee market price stability, and hopefully improve product quality. For this to be possible considerable efforts should be made to train the farmers and make them aware of the important potentialities this project may have to increase their earnings. In order to develop these capabilities and foster cooperation among private producers, the role of the public sector (e.g. training programs, awareness campaigns, oversight, and so on) is very important. A key role in this regard may be played by the Growth Centers that work under the support and the supervision of UNIDO. Interviews at the Makeni Growth Center reported that the center is organizing training programs that may be useful in several respects. Indeed they are set up not only in order to help the local producers to acquire the required skills to run production and learn how to use necessary equipment, but also to make them aware that they can produce at a higher level than self-sufficiency and make monetary profit from their activities. The Growth Center can therefore represent not only a convenient location for production, but also a point where local producers meet with other producers, exchange ideas and share experiences, increase awareness about their potentialities, and (not least) obtain important information about how to run their businesses.

\section{2) Poor physical infrastructure}

The availability of well-functioning physical infrastructure is very important for export growth. Poor infrastructure indeed increases both production and transaction costs, and may inhibit entrepreneurial activities. It increases production costs because if infrastructure such as roads, ports, electricity, water, sanitary, are not publically provided, their cost must be borne by the private producer. All such facilities are necessary for the production itself, and constrain in

\footnotetext{
2 An effort in this direction is offered by the 2010 Smallholder Commercialization Programme (Ministry of Agriculture, Forestry and Food Security, 2010), which aims at improving the production scale, enhancing productivity, value addition and marketing for smallholders, reducing households' vulnerability to negative shocks and disasters, improving increasing food security and nutrition of poor people, improving physical access of small farmers to markets and to rural financial services.
} 
different ways the different sectors in the economy. Furthermore, poorly functioning infrastructure increases transaction costs. First they obstruct the linking channels between upstream and downstream firms, e.g. they make transportation and communication difficult and costly. Second poor infrastructure even hinders the organizational, managerial and logistic capabilities of the firms. This is widely confirmed by other countries' experience, so that improving physical infrastructure ranks among the priorities of any government involved in export promotion (see Belloc and Di Maio, 2011) and such interventions are among the less controversial policies to favor exports.

Sierra Leone suffers from very weak and dysfunctional infrastructure, although the government and development partners are currently investing in several projects. There are few roads in good conditions although a range are under construction, the power supply is not continuously ensured, clean water provision is sometimes a problem, and port facilities need improvement.

Representatives of the private sector suggest that improving domestic infrastructure is crucial to increase profitability in several sectors. This is particularly important for the agri-business sector. During interviews, entrepreneurs in the processed food sector (fruit juice) stressed that lack of reliable provision of water and electricity represented a major constraint to efficient production. Huge amounts of production get lost because producers do not have the ability to preserve and store them, due not only to the lack of the necessary equipment but also to the absence of reliable power supply. This is also an obstacle to the will to further increase production.

The effect of the lack of efficient infrastructure is particularly dramatic in fisheries. This was the origin of a nine-year ban on Sierra Leonean fish export to the EU starting in 2000: the fish caught and processed by the locals was unlikely to meet the quality standards for exporting to the EU due to lack of the necessary equipment for storage and preservation and, moreover, of a laboratory to test the quality of the product and properly to certify it before export. The ban was removed in December 2009, but the situation has not substantially improved. Since the necessary infrastructure for storage, cooling, preservation and transportation are still not locally available, the fisheries sector is currently under the control of foreign investors (mainly from China and the Republic of Korea) that catch the fish in the Sierra Leonean sea, mostly catching and then transshipping off-shore to sell abroad. This is particularly worrisome for a number of reasons: first, the considerable fish resources that represent one of the most important potentialities of Sierra Leone are not appropriately exploited by locals (this sector almost does not yield benefits to the domestic 
economy, all the earnings being captured by foreign companies); second, the overexploitation that is carried out by international investors (that is not monitored by any environmental protection program) is likely to destroy the domestic natural maritime heritage in the medium to long run and, as a consequence, to compromise the possibility that Sierra Leonean fishermen will be able to reap benefits from it in the future. During interviews, authorities stated that important local infrastructure projects are under construction. But the time they will be ready is currently not clear.

In the tourist sector, entrepreneurs also complain of the lack of acceptable sanitary conditions, and assess that liquid waste and refuse management are sometimes inadequate (in particular we are referring to interviews with entrepreneurs in the tourism sector). Tourism infrastructure was greatly destroyed during the rebel war. Restaurants and hotels prepare, handle and serve food and drinks, often to foreign customers that are use to high level standards. Not respecting basic sanitary and hygienic norms is likely to imply high risk of infections and to reduce the number of foreign travelers willing to choose Sierra Leone as a possible destination. This is crucial because it increases the cost of hotel and restaurant services since the private investors have to bear, themselves, the total cost of cleaning, disinfection, clean water provision, and so on. This obviously dramatically reduces the price competitiveness of Sierra Leone as a tourist destination.

\section{3) Difficulties in quality and other standards compliance}

Among the major challenges developing countries have to face, in the new international context, is that of quality and other standards compliance. Obtaining the product quality, health and sanitary certification has indeed become a key obstacle for local firms, some of which may be otherwise ready for exporting. International standards are increasingly demanding, especially for exporting to the EU and North America. Firms from developing countries are nowadays forced to improve quality of their products to obtain the certifications for accessing to the Global Value Chain, especially in the agro-industry. In Sierra Leone, even if several firms meet the standards for domestic consumption, several steps must be taken to reduce the gap between the actual quality of domestic products and the standards required for them to be exported (for many domestic firms they are still far from being reachable). International quality standards apply to all agricultural products exported by Sierra Leone, including cocoa, coffee, ginger, cashew, cassava and rice. The process of achieving the international quality should involve both the private and the public sector. Regarding the first, the awareness of the problem under consideration must be fostered. Often local producers are not aware of the fact that, in order to export their products, they must meet higher 
standards than those required by the local market. In the past, quality standards were not imposed, so local producers are not used to them. Second, even when they are aware of this issue, they may not have the capabilities to deal with it. In some cases learning the necessary skills to improve product quality is easy (e.g. ginger), in other cases, the procedure for quality improvement is much more complicated (e.g. cocoa). But even if these two obstacles (lack of awareness and of skills and capabilities) were removed, one should consider that there are important bottlenecks to be deal with. One common problem, that was emphasized not only by local entrepreneurs, but also by public officials (such as representatives of the Commodity Market Monitoring Unit and the Standard Bureau), is the fact that the necessary equipment to improve quality is not available to producers: for instance, cocoa producers do not typically own cocoa dryers. In this sense the experience of the Growth Centres managed by UNIDO (that we have also mentioned in section 4.1) may offer a good opportunity to improve the current situation.

Also, much can be done to enhance facilities provided by the government and the governmental agencies (again the Commodity Market Monitoring Unit and the Standard Bureau): accredited laboratories and equipment for testing are currently not functioning, so that product inspection must be provided by the international partners. Staff training programs are not in place and cooperation with other institutions (e.g. the University) is still rare and not formalized. Cooperation with foreign partners would be particularly important in order to get acquainted with certain technical requirements. Programs of training abroad (for instance in China, India, or Brazil) by local staff of the relevant authorities (the Standard Bureau, for instance) may be important but should not be confined to occasional and brief experiences. An important role again can be played by UNIDO via provision of technical assistance. This kind of support and cooperation should be enhanced.

Interviews with private stakeholders suggest that the quality issue is deemed very serious. Entrepreneurs in the processed food sector complain that the quality of the inputs they purchase from local producers, who usually sell their products (e.g. rice) for domestic consumption, is too low to be used to obtain a final product (e.g. baby food) able to meet international standards. An entrepreneur in the agri-business (ginger) suggests that the main problem is the lack of awareness and of skills and capabilities, because the testing equipment is in most cases directly provided by foreign partners. Moreover, a shared opinion hints at the lack of coordination among authorities. An example may help clarify this point: there is some confusion whether the responsibility for testing water quality is with the Standard Bureau or the Ministry of Health. 
Finally, the quality issue is strictly related to the problem of poor infrastructures highlighted above. It is possible (for example) that the product meets the requirements at the moment it is tested, but problems in transportation delay the shipment so that the product deteriorates by the time it reaches its destination. As already emphasized, this is particularly crucial in the fisheries sector.

\section{4) Problems in the financial system}

Constraints to credit access represent an important barrier to exporting, especially when the domestic economy is weak. In all the economies, entrepreneurs need capital to finance their business. Possible (formal) sources of finance are: banks, donors, micro-credit, and international partners (e.g. equity financing). In Sierra Leone so far private investors have strongly relied on the help of the donor countries (e.g. the Netherlands). Establishing domestic-foreign partnerships is a promising way to respond to the financial needs of producers in the absence of a well-functioning local credit system. Yet, finding reliable partners may be a difficult and time consuming task.

In such a situation of lack of capital, credit market institutions have a central role in providing the system with the necessary credit the entrepreneurs need to finance profitable investment. This is however, at present, very difficult for several reasons. Investments in domestic production and export activities often incur a very high risk, due to the weak economic (both demand and supply) conditions they face. Furthermore, the actual level of risk is sometimes difficult to evaluate. High uncertainty and difficulties in risk-opportunities evaluation have led the financial institutions to assume a very conservative attitude, restricting credit to a small number of companies, limiting the amount of credit to lend and setting very high interest rates. Hence local producers, exporters and potential exporters face two major financial constraints: the availability of credit and the high cost of borrowing. Since sometimes potential opportunities for economic success are concrete, the lack of credit represents a key bottleneck to exporting. Important market failures (lack of coordination among the government, financial institutions and the private sector) further worsen the situation, as we will better explain at the end of this section.

The problems in the financial system are even magnified when they are considered together with the problems stemming from informality. Informality is widespread in Sierra Leone and also involves the credit sector (e.g. Jalloh, 2003). Intervention aimed at reducing the diffusion of informality is among the priorities of the national Central Bank. The reason is that a large informal 
sector exacerbates the financial system problems because they do not maintain formal records (such as formal bookkeeping).

An underdeveloped financial system is a major obstacle to trade not only because it raises barriers to credit access for local producers and directly affects the production costs increasing the cost of capital, but also because it may increase the transaction costs for international partners of the domestic firms. Simple and common operations that international entrepreneurs investing locally need to make, such as international payments to or credit gathering from domestic producers, become difficult and costly when the system is weak and inefficient. The same is true for any partner of the firm. For instance, the upstream firms may in turn incur payment problems at several stages of the production process resulting in delays in the delivery of the outputs used in production by the downstream firms. Hence, a weak financial system is likely to negatively affect domestic and international firms' profitability, not only directly but also indirectly, generating a chain of failures and inefficiencies.

The credit problem is particularly serious in the agricultural sector where the profitability is extremely uncertain and the land tenure system represents an obstacle to using land as collateral (see section 4.5). Investors in the agricultural sector complain the lack of necessary equipment, such as tractors. This is crucial because it negatively affects profitability in the agri-business. Where production potentialities are not entirely exploited, credit supply to local farmers would allow them to purchase the proper machinery that is necessary to improve the farming techniques and make higher profits.

Currently, there is no Export Credit Guarantee or Credit Risk Insurance Scheme (NES, 2010) that may alleviate the problem. This is why one international investor that we interviewed during the scoping visit and is currently producing in Sierra Leone has rather opted to locate its business in the First Step EPZ: starting production in the EPZ has made it possible to obtain capital from the international investor financing the EPZ and starting a partnership. Consultations with government officials suggest that the government may substantially intervene in this matter, for instance by implementing the Credit Reference Act (to alleviate credit risk evaluation problem with the banks) and making business registration easier (one stop registration).

Again the situation is made more serious by the fact that several issues mentioned above are strictly interconnected. An insightful example was suggested during the interviews regarding cocoa production. In this sector, farmers produce the cocoa, middlemen purchase it and sell the cocoa to the exporters that offer the product on the international markets. The cocoa that is sold by the local 
farmers is of low quality. Indeed, as already suggested in this report, cocoa farmers have no appropriate skills and equipment to improve the quality of cocoa and to process it (drying etc). The cocoa buyers are not only exporters of this product but also general traders who make most of their income from importing consumer goods. Often the cocoa is used as an exchange good by producers to obtain other products in the absence of liquidity (e.g. credit from the financial markets). This leads buyers to accept the low quality cocoa available in the short run (when the exchange goods are needed to buy other commodities) rather than waiting for the good quality product that would require investments in terms of resources and time. Whilst improving the quality of cocoa will increase profits throughout the value chain, the absence of credit on the part of the sellers who are often in a position of distress selling, means they cannot invest in either the skills or equipment to improve the quality of cocoa. Meanwhile, buyers in Sierra Leone, who often face constraints on their business due to the lack of foreign exchange availability, are eager to have any tradable product and so will buy cocoa of any quality. They do not have sufficient trust in the cocoa producers, nor often enough available resources of their own, to make substantial cocoa investments either. There is, in other words, a coordination failure that implies that the system is stuck at the low equilibrium and there is no incentive to move from it, because none of the parties involved in the transaction trusts the other party.

\section{5) Issues concerning the land tenure systems}

Regulation of land use is fundamental in an agriculture-based economy such as Sierra Leone: it determines the availability of land for local and international investors and also strongly affects the cost of land use and the ease of doing business. Sierra Leone is a country abundant in fertile land and labour; it has, as a consequence, a comparative advantage in agriculture. However, there is a substantial amount of land that each year remains uncultivated (FAO, 2006, suggests that this area in the after war period was around 4 million hectares).

From our interviews it has emerged that an important obstacle to the development of the agricultural sector is the land tenure system, which is based on a two-track scheme, namely, the colonial land system, which is in force in the Western Area, which includes Freetown, and the customary land system, which prevails in all the other areas (on the latter see Johnson, 2011).

The customary land system, which has the ultimate goal of preserving land ownership for the indigenous (traditional) landholders, by its restrictions on land transfers in general and on land use 
by non-natives, has the negative effect of increasing substantially the costs of land to non-natives. Furthermore, the system increases uncertainty of property rights in land ownership and use, and diminishes the ability of land to be used as collateral in credit markets. As a consequence, foreign investors' access to land use is discouraged by the high transaction costs that they will incur when attempting to start an agricultural activity and by the great uncertainty in terms of time length they will be able to rely on the use of a certain amount of land. There are a number of proposals to reform the land tenure system in Sierra Leone, including enabling a voluntary evolution of the customary land tenure system towards privatization (see, again, Johnson, 2011).

Sierra Leonean entrepreneurs and government officials are aware of the problems here discussed and changes are, indeed, under consideration, although our interviews did not reveal a clear and convincing strategy. Ensuring optimal access to land of both local and international investors is crucial to Sierra Leone reaping its full potential in agriculture and other sectors as well. At the same time, the current land owners should be fairly compensated and directly involved in decisionmaking on the use of land that is often their only means of subsistence (besides their own labour). The challenge is to balance these two aspects.

\section{6) Low awareness about opportunities}

To increase export, it is important to improve the private sector awareness about the opportunities that come with international involvement. Although, as pointed out above, Sierra Leone is facing several capacity constraints, there are, in some sectors, opportunities to be exploited. Local producers and investors need to become aware about their possibilities to increase quality and quantity of production in order to identify targets and potential business partners. If awareness is properly enhanced, bottlenecks can be removed, so that the demand and the supply could meet at a higher level. There are several aspects that can be highlighted in this respect.

A first example relates to the agricultural sector, where the local farmers have, often, no skills and no equipment to improve the quantity and quality of their products and to process them properly (cocoa, rice). Enhancing quality might be profitable because it would allow local producers to sell their products at higher price to the exporters, and local producers should be made aware of this. Yet there is a coordination failure traced to lack of awareness, of trust and of proper information with the result that the system is stuck at low quality equilibrium with no incentive to move from it for each of the parties involved. 
A second interesting example is provided by the mango production. Sierra Leone is rich in mango trees that produce large amounts of fruits almost without cultivation. Farmers are often unaware of the potential that such a considerable amount of mangos may offer, so that they do not gather these fruits from the trees, do not properly store them and let them get spoiled. Furthermore, even when fruits are gathered, they often cannot be stored properly. The demand for mango fruits that was generated by the international fruit juice producer located in the First Step EPZ made local farmers living in the area to learn that they can in fact sell their fruits and make some earnings. This story is illuminating because it reveals that huge potentialities are there, and farmers are sometimes just unaware about how to exploit them.

An important activity is carried out by the Growth Centers funded and continuously supported by UNIDO. These centers, beyond providing equipment and training programs, help the local farmers to become aware of their potentialities and to learn how they can produce and sell their products. SLIEPA (as are other entities, such as the Chamber of Commerce) is also involved in several programs targeted to foster awareness about export opportunities. To pursue this objective, different instruments are used, such as: supporting participation of local producers in trade fairs and shows, and holding meetings in the main district capitals where reports produced by SLIEPA and other material on foreign markets are delivered. Moreover SLIEPA has a modern information trade centre where private actors can get any kind of information, access to the internet, etc., and which also serves as a mediator between public and private sectors. Yet there are aspects that can be improved. To begin with, it is important to increase accessibility of documents and information by reaching directly the rural areas. During the interviews this issue often came up. In the case of large firms interactions are easier, also because large firms are more likely to be aware of the business opportunities they can exploit. With small and medium size firms communication is much more difficult. Not only they rarely make use of the services that SLIEPA directly provides, but also they are not very likely to attend trade fairs and workshops. Also communication between large and small firms is in general absent. The lack of awareness is particularly important for policy effectiveness. Indeed, for instance, ECOWAS is not an automatic custom union. The trade liberalization scheme is such that, in order to enjoy the concessions from the custom union, firms must register to export. However, only a small number of firms apply for registration mostly because there is a lack of awareness or because the majority of firms gravitate towards the informal economy. This emphasizes an important message that we will stress in the second part of the report: policies (in our case export promotion policies) may be totally ineffective if they are not accompanied by feedback from the private sector. From this it follows that the latter need not only 
to be informed and become aware of the policy instruments the government is implementing, but must also believe in the effectiveness of the policy instruments and so be willing to make use of them.

\section{7) Business environment}

A favorable domestic enabling business environment is crucial for present and potential exporters. The business environment involves several aspects and includes all the factors that affect investment feasibility and profitability, including, for instance: an effective judicial system, an efficient regulatory environment, the availability of skilled and specialized workers, the accessibility of reliable information on procedure and fees for licenses, and the burden of formal procedures to start a business.

According to the "Doing Business" survey (World Bank, 2011) Sierra Leone in 2011 (as well as in 2010) was ranked 143 out of 183 economies in ease of doing business. The ranking is determined relying on the evaluation of the ease of doing business in the nine stages that characterize an entrepreneurial project, namely: starting a business, dealing with construction permits, registering property, getting credit, protecting investors, paying taxes, trading across borders, enforcing contracts and closing a business. With respect to 2010, the rank of Sierra Leone has improved regarding some of these stages and for others. In particular, the rank has improved with regard to dealing with construction permits (the rank goes from 171 to 166), registering property (from 175 to 169 ), paying taxes (from 161 to 159), trading across borders (from 137 to 136). The sub-indices (such as the number of procedures, number of days necessary to deal with procedures, the associated costs and so on) affecting the rank in the various stages have remained stable for the last two (paying taxes and trading across borders), therefore the upgrade of Sierra Leone in the ranking of world economies depends on what has happened in other countries. In the first two, the only sub-indices that have improved are: the number of days necessary to dealing with construction permits and to register property. The stages where Sierra Leone's position has worsened are: starting a business (from 58 to 61), getting credit (from 125 to 128), protecting investors (from 27 to 28), enforcing contracts (from 143 to 144), closing a business (from 147 to 149). Interestingly relatively to starting a business, all the sub-indices have remained stable except the cost of starting a business (\% of income per capita) that has decreased (thus ranking improved). All the sub-indices affecting the ranking in the remaining stages have not changed since 2010 . 
The interviews conducted with foreign entrepreneurs in the processed food and in the tourism sectors have clearly revealed an interesting fact: the reasons why the investor has chosen Sierra Leone as the destination of his business were not always related to an evaluation of the business potential of the country, but for personal reasons (e.g. family connections). This suggests that, sometimes, success stories happen by chance and, hence, Sierra Leone has to learn how to reap benefits from them by keeping those investors in the country (besides, the more ambitious and longer term goal of attracting new investors for business reasons). Offering a favorable business enabling environment is crucial to this aim. Interviews suggest positive opinions by foreign investors locally producing, who testify that the entrepreneurial context Sierra Leone has to offer to the businessmen is gradually improving after the rebel war, especially regarding political stability.

A promising effort under-way by the government of Sierra Leone is the establishment of the "one stop center" where entrepreneurs can submit requests and obtain all the permits they need to do business. While public officials (in the Ministry of Trade and Industry) told us about this project, interviews with producers and investors revealed it is not operational yet or that they are not aware of it.An important and too often under-considered element that deeply affects the economic environment of Sierra Leone, as that of other LDCs, is the significant presence of NGOs, donors and other international organizations. Sometimes the interaction between these actors and the local firms may create distortions that the government should try to minimize. A clear example of how difficult is the management of the economy in Sierra Leone comes from an example concerning the rice sector. The pricing of rice has been an issue in Sierra Leone for a long time. Several interviews with both public officials and private entrepreneurs have revealed a complicated picture. After the rebel war the price of rice in Sierra Leone was below its fair value (mainly because of the stronger bargaining power of the international buyers with respect to that of the local producers). The Rice Committee was established to set a fair price considering several factors: (a) the world price, (b) the domestic situation, (c) the situation of the neighborhood markets (mainly Ghana and Liberia), and (d) the dynamics of the exchange rate. The price at which producers sell the rice should be not below the indicated price. However, interviews with local producers have highlighted a different (and somehow opposite) problem that is currently in place and is related to a perverse effect of the the World Food Program (WFP). During one interview, it was pointed out that this may have adverse effects on local producers of processed food (for instance, baby food) for two reasons. First, when the WFP buys rice locally it bids more than the market price. Unfortunately this has a negative impact on the local producers of processed food 
that need rice as an intermediate product. Second, the WFP also provides processed food products (for instance, baby food) that thus competes with the locally produced one. Since the WFP can access cheap intermediate inputs produced on a mass scale (especially agricultural ones) on the world market and because UN packaging and transporting are not included in the cost calculations, its products are cheaper than the domestically produced ones.

\section{5) Suggestions to maximize effectiveness of NES: the design}

In this section, we begin discussing some suggestions for improving the design and the content of the NES relying on the best international practices as for export promotion policies and on the main findings discussed in the previous sections. The suggestions are: 1) improving knowledge about the supply and the demand side of the economy; 2) setting the sequencing and increasing selectivity of the export promotion policies; 3) enhancing coherence with other government policies.

\section{1) Improving knowledge about supply and demand side}

Any export promotion strategy must be based on the clear identification of the country's comparative advantages. The latter indeed determines the role of the country in the international arena and its relative position vis-à-vis other competitors. This is why a clear identification of the country's comparative advantages is the necessary pre-condition for any intervention in the export domain to be effective. Comparative advantage identification requires further improvement to the knowledge about both the supply and the demand sides of the economy.

The NES presents sectoral analysis of each targeted sector. While these analyses are useful, there is a need to go into more detail. As for the supply side, what is still missing are firm-level data on production and distribution characteristics in each sector/industry and in each stage of the value chain. One would like to have as detailed as possible data on domestic and foreign producers. It would be also advised to have data not only on currently exporting firms but also on the firms that are planning to start exporting. These data should include, among other information, the following: sector, type of activity, number of employees, sales, number of different goods produced, markets, type of relation with local and foreign firms (i.e. position in the value chain), and ownership structure. 
At the same time, it is crucial to enlarge the knowledge about the demand drivers and the dynamics in the domestic and international markets. If the objective is to increase exports, this requires a clear understating of the rapidly changing patterns in world demand. The more the government and the private sector become aware of the evolution of the destination markets, the more quickly and (hopefully) the better they will be able to react.

Different ministries and government agencies (such as SLIEPA, for example) are already deepening their efforts in the suggested direction. Nonetheless, more should be done. What seems to be the first step in improving the understating of both the supply and the demand side of the economy is pulling together the different data sources available. Indeed, as already highlighted in section 4.1, during our scoping visit, it clearly emerged that important pieces of information are already there but they are dispersed in different ministries and government agencies. Pulling these data together would be an important and immediately feasible first step. Building on the current knowledge, the next step would be to expand upon the already available data. The collection of data and information about the population of domestic and foreign firms and the characteristics of the exporting markets is crucial for both the design of effective export promotion policies and for allowing the possibility of evaluating them. Still, while other countries' best practices convey important information that may serve as a guideline to domestic policy formulation (for a discussion see Cimoli et al., 2009; Belloc and Di Maio, 2011), it is these domestic economic policies tailored to the local context that will ultimately be implemented. Policies that have been successful in one country may be a total failure in a different one. ${ }^{3}$ Maximizing the knowledge of the domestic economy and its interaction with the international environment represents, as a consequence, a building-block — that is, an important input—for any domestic policy design.

\section{2) Sequencing and selectivity}

Among the various targets a government pursues, it is important to identify which of these are short run objectives and which apply to a longer run horizon. As we have argued in the previous subsection, the understanding of the current situation is crucial for the design of effective export promotion polices. This is clearly only a first necessary condition but it is crucial also because it allows one to clearly identify which are the relevant binding constraints for the local economy. The

\footnotetext{
${ }^{3}$ Following Robinson (2009) one may add that the same reasoning should be applied as for the understating of the political context in which the policy is designed and then implemented.
} 
constraints obviously refer to different domains: they may concern the availability of resources (labour, capital, and land), technology, institutional capabilities, etc.

The presence of binding constraints implies that selectivity is necessary for making any government intervention, at least potentially, effective. Obviously selectivity implies choices and thus the possibility of mistakes, which may be very costly. This is (of course) not an argument against intervention but it has to be considered as an unavoidable factor in deciding any type of government intervention.

At the same time, a correct understating of the current economic situation contributes to identifying also reasonable long run objectives. The possibility of determining the sequencing (i.e. the timing) of these different objectives is strictly related to the identification of static and dynamic comparative advantages. According to the economic trade theory, static comparative advantages indicate what the country is currently relatively more efficient at producing when compared with other countries. In this sense they are to be taken as given in each moment in time. Dynamic comparative advantages instead refer to the possibility that a country develops other and different comparative advantages in the future. The challenges here are several. These include the ability to identify which are the dynamic comparative advantages likely to develop, which are the ones easier to develop given the static advantages and how it is possible to achieve these objectives. While we cannot discuss the several theoretical arguments related to this choice, what is important to emphasize here is that the realization of dynamic comparative advantages may be costly. Usually dynamic comparative advantages are ex-ante unknown and are the results of the deliberate policy choice by the government and of specific investment by the private sector. The crucial point is then the acknowledgement of the fact that if one aims to achieve both short and long run development objectives, priorities must be set taking into account resource constraints. The latter are in fact always present.

In this respect, a development strategy based on the exploitation of natural or mineral resources has to take into account the inherent scarcity of these endowments and thus the need to device a long run strategy that considers a time period when these resources will be no longer available. The long run objectives should include avoiding exclusive reliance on nonrenewable resource dependent production.

The achievement of long run objectives also requires proper consideration of the available government and private sector capabilities, the supply of capital and other inputs, and the nature 
and state of domestic and international demand. Moreover, one has to consider the evolution of the economic environment and devise the best way to cope with it.

Given the inherently uncertain nature of the future economic conditions, it is clear that the accumulation of capabilities that are related to the development of long run objectives is more difficult. In this sense the importance of development of flexible and generic (rather than specific) skills and capabilities could not be overemphasized. Nonetheless, the aim should be balancing the need of the short and medium-long run requirements.

This argument suggests that much care should be paid to avoiding the risk that policies designed to exploit static comparative advantages (short run policies) hinder the attempts to develop dynamic comparative advantages (longer run objectives). There are several reasons for which this may happen. In particular, in developing countries, which are characterized by abundance of natural resources (and thus enjoying comparative advantages in production of traditional sectors such as mining, agricultural, etc.), policies designed to increase the intensive margin of export in the short run may conflict with the longer term objective of increasing the extensive margin of export, because of resource constraints. ${ }^{4}$

\section{3) Policy coherence and interactions}

Not only should export promotion polices be coherent as regards the short and the long run objectives, but they also need to be coherent with respect to all the other government policies in place. Similarly to the case of other African countries, the government of Sierra Leone is in the process of developing numerous polices in different domains. This renewed interest in government intervention is, among other things, due to the acknowledgement of the disappointing results of the so-called Washington Consensus approach and to the increasingly shared view among economists and policy makers that a new approach to development characterised by the cooperation between the government and the private sector is needed. Moreover, in the case of Sierra Leone, this is also part of a more general need to re-build the institutional architecture after the rebel war.

\footnotetext{
${ }^{4}$ Obviously this is not a necessary outcome. A well managed natural-resource based export sector may indeed favour the possibility to design ambitious policies devoted to creating dynamic comparative advantages. For an example, see the case of Botswana for the management of diamonds or the Chilean case for the use of revenues from the copper industry.
} 
At the moment, there are several policies under consideration by the government, most of them in their design phases and likely to be approved soon. Among these, of importance are various sectoral policies (for instance, the Tourism Master Plan, the Incentive Bill, the Trade Policy and its Action Plan, and the Competition Policy) and the NES. The increase in the number and complexity of policy documents calls for an effort to ensure coherence amongst them as an important element for a comprehensive development strategy. Moreover, there is the additional need to ensure that the different policies are in compliance with international agreements to which Sierra Leone has acceded. The increasing complexity of these agreements suggests that a further improvement in the capabilities of the government in the design of effective policies is required (see section 6.1).

While the interaction and coherence between export promotion policies and other policies is important, their relationship with industrial policy in particular is crucial. By industrial policy one usually is referring to the set of policies (innovation and education policies, trade policies and sectoral and competition polices) employed by governments to induce structural change and industrialization (UNECA, 2010). It is largely agreed that industrialization is one of the key factors for development. One of the main reasons is that industrialization allows for the increase in efficiency and thus for the possibility to diversify production. From this it follows that the NES and the industrial policy should closely interact and be seen as complementary policies. Only a coherent and comprehensive policy design will make the NES effective.

\section{6) Suggestions to maximize effectiveness of the NES: the implementation}

The success of the export promotion policies included in the NES rests on a number of critical elements concerning implementation. In what follows we discuss four main recommendations that we deem important to increase the effectiveness of the NES and that follow the evaluation of the findings that emerged during the scoping visit.

\section{1) Government and private sector capabilities need to be improved}

The first element concerns the need to improve the capabilities of both the government and the private sector in terms of ability to implement and follow the different policies included in the NES (see also section 4.1). This is a particularly important challenge. While one should not forget that 
the current gap in terms of capabilities and knowledge which characterizes the country is in part due to the recent war experience, there are also some structural weaknesses concerning human capital formation that should be taken into account and readily addressed. Moreover, the need to focus on improving capabilities is also reinforced by the fact that the international trade context in which the country is now competing is rapidly changing. In addition, the international institutional context is becoming increasingly complex and thus the ability of the government to manage such a situation requires continuous effort and improvements to be effective.

As we already mentioned in the previous section, Sierra Leone's government, similar to governments in other African countries, is developing a number of new policies to regulate and intervene in different economic domains. The list is already long and is getting even longer year by year. To have an idea of the difficulties that the government is about to face just in terms of policy coordination, one should consider the case of trade policy. Trade policy management has to simultaneously cope with and consider the constraints set by the WTO, ECOWAS, and the Mano River Union, to which Sierra Leone belongs, and the bilateral agreements (AGOA and EBA). In particular, there is no doubt that the next substantial challenge Sierra Leone has to face will involve the ECOWAS negotiations with the EU on the EPAs. There is nowadays considerable academic and policy debate on the possible effects of these agreements. Government officials need to be prepared to take an active part in the various trade negotiations. For instance, improving government officials' capabilities concerning international arrangements and negotiations is needed to make the country benefit (or at least not lose) from exemptions and special treatment concessions within the EPA agreements.

Another domain in which the importance of the improvement of government capabilities clearly emerges is regulation. The government of Sierra Leone has recently designed a new regulation policy. Regulatory activity is quite complicated in any country: in a country like Sierra Leone, rich in natural resources and characterized by the presence of large foreign companies, it is even more demanding. The possibility of large projects to be implemented in the country (for instance, the Addax Project) usually offers not only important growth opportunities but also challenges to face; hence, exploiting such opportunities requires proper management and control by the government. Unfortunately, it seems that, at the moment, the necessary capabilities are not yet there. There is no doubt that there are well-equipped staff members in the ministries and in the government agencies. But one has doubts about the adequacy of the numbers, relative to the needs, to ensure that various investment projects are subjected to appropriate supervision of the 
government. Indeed, the gap between the currently available capabilities in the government and the ones required to meet all the challenges ahead is, if anything, expected to increase.

As for the private sector, things are no less complicated. The competitors in the international arena are increasing in number and strength and the rules of the game are rapidly changing. There is a need to increase the private sector awareness about business and production best practices. Much more than in the recent past, it is now absolutely crucial to have a clear understanding of what is happening in other countries and in world markets. Respondents to the interviews (see again section 4.1) reveal that local entrepreneurs are not well prepared to be competitive at the world level. Government agencies are fully aware of this weakness on the side of the private sector and programs and attempts aimed at improving the situation are underway. These efforts are promising but the general impression is that there is still much that needs to be done. The importance of increasing private sector capabilities rests on the fact that the export promotion policies contained in the NES are designed assuming that the local entrepreneurs would react in a market-oriented and competitive way to the policy incentives. Yet, there are several reasons for which this will not necessarily happen. For instance, to successfully implement the policies included in the NES it is first required that the domestic private sector progressively abandon subsistence production and adopt a market-oriented approach. This implies that agents need to be trained to become able to reap the benefits of the policies and to compete at the international level.

\section{2) The responsibilities of each actor and the objectives of each policy need to be clearly defined}

The NES is one of the numerous policy documents that the government of Sierra Leone has designed in recent years and is now about to be implemented. Several institutions and actors have taken part in the design of the NES and some of them will also conduct the implementation of the policies. In order for the implementation process to be successful and errors and delays to be minimized, it is crucial to clearly identify the responsibilities that each actor and institution should take.

There is clearly a momentum for policy design in African countries. In this sense, the challenges that Sierra Leone is facing in terms of managing policies are common to other countries in the region. While a shared view supports the necessity of re-designing the government 
intervention in the economy through these new policies, also clear is the importance of identifying the specific responsibilities and the tasks of the various ministries and government agencies.

The fact that the complexity of the government strategies is increasing reinforces the necessity of clearly assigning responsibilities to particular ministries and government agencies in the implementation of the various policies. While this may require that the central government give greater autonomy to governmental agencies/bodies in the implementation of the policies, reducing the direct control of the centre, it would have the advantage that the results of the activities of the autonomous agencies and bodies could be more easily and transparently evaluated.

The clear assignment of responsibility is crucial in order to be able to assess the effectiveness of policies, to coordinate the various policies with each other and to determine how to intervene when it becomes necessary to modify a policy. In other words, coordination and responsibility assignment are not only important per se but also in the light of gearing a feedback mechanism to progressively tailor the policy design to fit the context on the one side and the targets on the other.

\section{3) The impact of policies needs to be carefully evaluated}

Any policy intervention needs to be properly evaluated. There are several reasons why this is important.

First, policy evaluation allows us to verify whether or not the policy is achieving the desired results. This is important because, in case of success, it favours the increase in the support to the policy and the awareness of the private sector about the policy itself. If a policy is shown to be effective then the willingness to make use of it is likely to increase, and this, in turn, is expected to make the policy even more effective. Indeed an important step in the implementation of any policy is the necessity to make agents aware of the policy content and to be outspoken and explicitly responsive in supporting it. Obtaining a positive response to a policy from the private sector is not easy because it often involves costs (in terms of learning costs, legal and bureaucratic procedures, time, and so on) to be borne by the recipients of the policy. The latter will not be willing to pay these costs (implicit or explicit) if they do not fully understand the policy or if they believe the policy is unlikely to be effective. One of the main weaknesses of several export promotion strategies is that firms do not fully take advantage of the available policies. Indeed, many studies have emphasized that the lack of awareness by the local entrepreneurs contributes to the partial failure of several export promotion initiatives. Awareness about export promotion programs can be 
enhanced by interventions on three distinct but complementary aspects: (a) educational (seminars, workshops, training programs), (b) operational (information about technical standards, customer lists, commercial legislation), and (c) promotional (consultation, advocacy, and marketing). ${ }^{5}$

Second, it is necessary to understand how to modify the policy when it becomes clear this needs to be done, in order to fix weaknesses and bottlenecks that impede its proper functioning. Evaluating the effects of the policy will help identify the necessary changes in both the policy itself and in the environment. The effectiveness of policy intervention is very much related to the ability to modify it if needed.

Third, making evaluation part of any policy intervention increases transparency and accountability of the agencies or ministries in charge (see also previous point). Once responsibilities are determined one wants also to know whether or not and to what extent a responsible agency has been executing its intervention.

While policy evaluation is crucial it is very difficult to implement. Empirical evidence (see, for instance, Belloc and Di Maio, 2011) documents a large cross-country heterogeneity in terms of evaluation practices, and the quality is in general quite low. Policy evaluation requires skills and capabilities, not readily available in most LDCs. This implies that policy evaluation may be very costly. Yet the benefits are large and likely to outweigh the costs.

The basic requirements for a correct evaluation of a policy intervention include the scheduling of the moments in time when evaluation should take place and the designation of the internal and external evaluators. As for the first issue, the timing of the evaluation activity needs to be known in advance by all agents involved in the policy implementation. It would be advisable to have, in addition to the final evaluation, also, one or more intermediate evaluation moments. These would allow a closer monitoring of the impact of the considered policy. The second important element to be considered is that the evaluation should be carried out both by an internal and an external authority. It is indeed crucial that the evaluation process involve different perspectives and thus allow several frames of reference.

\footnotetext{
${ }^{5}$ The availability of ICTs has been revealed particularly useful in enhancing awareness about and use of EPPs; but also close interaction between private and public entities through regular meetings is crucial (e.g. Spence, 2003). Widespread use of improved ICTs, therefore, cannot replace direct contact for relation-building and cooperation at different levels. The meetings with SLIEPA have confirmed that this is also the case for Sierra Leone.
} 
The result of the evaluation exercise should inform the discussion and the proposal of changes to be applied to the current policies, and all the stakeholders should to be involved in such a process. This observation leads to the following subsection.

\section{4) Private sector involvement needs to be encouraged and enhanced}

One important novelty which differentiates the new approach to government intervention in comparison with the past is the emphasis on the role of the private sector. There is indeed an increasing acknowledgement of the fact that any policy intervention requires the active participation of the private sector in order to be successful. The participation of the private sector is expected to be beneficial because it contributes first of all to better informing the policy design. Moreover, an active participation of the private sector is a necessary condition in order to facilitate policy implementation. The private sector can take part in this process in different forms: a firm can take part as a single actor or via associations and different types of organizations. Furthermore, entrepreneurs may participate in the design and implementation of the policy, not only by attending meetings and workshops but also by proposing interventions and suggesting possible crucial issues to be considered. As for the implementation, the involvement of the private sector is crucial in order to empower it to be a major judge of policy effectiveness.

SLIEPA and the government of Sierra Leone (through the regional and national ministries and agencies) have done significant work in this direction. However, during our interviews and meetings the need for further effort to increase private sector involvement in the implementation of the NES was clearly visible. There are important challenges in this area. The difficulties of reaching a physically dispersed entrepreneurial community and the problems related to costly communication should all be taken into proper consideration. It is our understanding that SLIEPA is taking actions to solve these problems.

In addition, one should consider that there is still very limited awareness about what role the private sector should play. The attitude to only respond to government's stimulus rather than to propose possible actions (and considering the government as the leading actor) seems still to characterize the behavior of the private sector in Sierra Leone. The reasons for such a situation may be several. An important one may be that the entrepreneurs are not aware of the possibility of interacting with the government and of the importance of their role at the various stages of the implementation process for policy success. On the side of the government this may suggest the 
necessity to find proper instruments to increase private sector willingness to participate as an active player. The instruments to achieve this result are potentially numerous but there are no clear indications on which ones better fit the context of Sierra Leone. It follows that only experimentation and the collaboration on the part of the private sector may be useful in this respect.

\section{7) Additional points}

In the following two subsections we briefly discuss two potentially important elements to be taken into account to improve the effectiveness of the NES.

\section{1) Improving cooperation among local producers}

As we have already argued, one of the main impediments to export growth is the supply constraint at the local level. To the extent that this is an obstacle to making the NES effective, the government should consider the removal of such constraints as part of the implementation strategy. Among the various strategies that may be adopted to reach this objective one should consider (as suggested by several entrepreneurs during the interviews) favoring cooperation among local producers to organize production and supply. There are several expected positive effects from this strategy.

First, increasing cooperation among producers would allow the exploitation of potential economies of scale. The small size of economic activity which characterizes Sierra Leone and, in particular, the domestic agricultural sector is associated with relevant firm/farm level fixed costs. The coordination of activities among different economic entities would allow reduction of fixed costs for each single producer. At the same time, coordination between suppliers of agricultural products would increase their bargaining power in markets and probably augment market price stability as well (see for instance the Smallholder Commercialisation Plan, Ministry of Agriculture, Forestry and Food Security, 2010). Making the stream of income generated by agricultural activity more stable would enable the producers also to better plan their investments. Finally, such an environment would increase the certainty of the supply of raw materials to the producers that use them as inputs into production. The latter, in turn, will become more willing to get engaged in long run relationships with local suppliers. 
At the same time, improving and making cooperation among firms more stable would also help the cooperation with the government (associations have stronger bargaining power than single firms) and thus make the private sector able to negotiate instruments or policies to overcome obstacles to exporting (e.g. quality standards). ${ }^{6}$

This argument suggests that since the NES is more effective in the absence of relevant supply constraints, favouring the cooperation among local producers will enhance the effectiveness of the NES itself.

\section{2) Diaspora}

One potentially important contribution to the implementation of the NES and, in general, of government policies for development may come from the Diaspora. The Sierra Leone Diaspora is characterized by an abundant supply of highly skilled workers that may well contribute to making policy implementation successful. The accumulated capabilities in both the business and the governmental domains may now easily become available to both local entrepreneurs and government officials. Diaspora people have been acquiring (during the years they have been working abroad) a full set of capabilities and contact networks that are now precious to the local economy. They may become a relatively inexpensive way to access the technology and knowledge frontier. World business practices that Diaspora people may import into Sierra Leone can be rapidly diffused to the local entrepreneurial community making it able to better react to the new challenges coming from the international arena. In this sense, the Diaspora would contribute to loosening the capability constraints we have mentioned in the previous sections. Similarly, there are numerous Sierra Leoneans that have worked in international organisations, who may provide useful knowledge to the government to help improve the design of policies and the management of the implementation process. Easterly and Reshef (2010) show that many of the successful exporting entrepreneurs in Africa had life experiences abroad even if not always related to business. These experiences are important because they provide exposure to the world "export business model", i.e. they had the opportunity to understand the importance of meeting deadlines

\footnotetext{
${ }^{6}$ In this respect one should also mention the fact that at the moment a situation of fragmentation and low membership of the producers associations and of the chamber of commerce seems to prevail. An effort to improve this situation is clearly needed because the government would benefit from a credible and largely representative counterpart.
} 
and being well organized, meeting customers' demands and accommodating their tastes, keeping contact with suppliers, developing a reputation for reliability and working to preserve it.

There is one last important and subtle point that should be mentioned. During some of the interviews we conducted, it emerged that there are doubts about the effective possibility to implement the strategy. Most worryingly, this scepticism and concerns have been raised during interviews with people who had an active role in the drafting of the NES. This suggests that there are important responsibilities on the NES: its implementation is becoming a test to verify the ability of the government and of the private sector to manage a complex strategy. Most importantly this will influence the confidence of the private sector about the possible success of other policies that the government plans to design and implement in the future.

\section{8) Concluding remarks}

This report is the result of a thoughtful analysis of the export promotion strategy by the government of Sierra Leone as described in the National Export Strategy (NES) document. Our research was divided in two parts. In the first one, we carried out a desk-review of the NES. The main aim was to identify the strengths and weaknesses of the document, among other ways by comparing it with similar policy documents from other African and developing countries. The second part of the research was a 10-day scoping visit to Sierra Leone. The objective of the visit was to gather, through meetings and interviews with public officials and the private sector, as much information as possible concerning the major challenges the country is currently facing and will face in the near future in terms of export growth, and to identify the key opportunities to be exploited in the long run. The ultimate goal was to provide advice to improve both the design and the implementation of the export promotion strategy of Sierra Leone.

This paper reflects these two parts of the research we have carried out. In the first part, we have described the characteristics and the content of the NES. As a first step we have described the main elements of the NES. We have emphasized its importance in the context of the renewed effort of the government of Sierra Leone to promote development and growth. We have also highlighted the element of novelty with respect to previous attempts to design export promotion polices in the country. Finally, we have pointed out some apparent weaknesses of the document especially in terms of clarity of objectives. 
In the second part, we have presented the main findings of our visit. We identified six main findings. These can be summarized as follows: 1) private and public capabilities are improving but they are still weak; 2) physical infrastructure is generally poor; 3) problems concerning quality and other standards compliance are still serious; 4) there are severe problems in the financial system; 5) there are unsolved issues concerning the land tenure systems; and 6) there is low awareness of local producers about export opportunities. As a last point, we have discussed the quality of the business environment and its importance for export growth. Next, based on these findings and on the desk review of the NES and other relevant policy documents, we have elaborated a number of suggestions to improve both the design and the implementation of the NES.

As for the design of the NES, in order to improve its effectiveness, we suggest that it would be useful to: 1) improve the knowledge about the supply and the demand side of the local and the world economy; 2) increase the degree of selectivity of the export promotion policies and to more carefully consider the sequencing between short run and long run policies; and 3) to enhance the coherence and the interaction between the NES and other governmental policies. We have suggested four recommendations about the implementation: 1) government and private sector capabilities need to be improved; 2) the responsibilities of each actor and the objective of each policy need to be more clearly defined; 3) the impact of each export promotion policy needs to be carefully monitored and evaluated; and 4) private sector involvement needs to be encouraged and enhanced. Finally we identified two other potentially important elements to be considered in order to make the strategy successful, namely: 1) improving cooperation among local producers in terms of production and distribution, and 2) taking advantage of the skilled Sierra Leone expatriates that could become a very a valuable resource for the country.

The NES is a well drafted document that clearly shows a genuine effort by the government of Sierra Leone to increase export. A careful analysis of the NES indicates that some of the export promotion policies and strategies that the government is about to implement are in line with the international best practices. Moreover, one of our findings is that the government is actively working to improve the business environment, which is a pre-condition for the NES to be successful, and this effort is generally acknowledged by the private sector. Our interviews detected a consensus that there were numerous opportunities in different sectors but that they were likely to fully materialize only in the medium to long run. In short, there were still major obstacles to be overcome to enable Sierra Leone to fully exploit its vast economic development potential. The main obstacles are on the supply side (production capacity and quality). This implies that most of the effort should be concentrated on removing the constraints to the expansion of production and to 
the improvement of product quality. These are the pre-conditions necessary to allow not only an increase in the export of traditional products but also the diversification of export which is the key to prosperous growth. Finally, our inquiry suggests that it is crucial to correctly understand how to exploit the current conditions (endowments, capabilities, opportunities) to bring results in the short but also in the long run. Coherence between exploitation of static comparative advantages and creation of dynamic comparative advantages is the challenge Sierra Leone has to face to make export become an engine of growth.

\section{References}

Belloc, M. and Di Maio, M. (2011) Survey of the Literature on Successful Strategies and Practices for Export Promotion by Developing Countries. IGC Working Paper 11/0248, June 2011

Cimoli, M., G. Dosi and J.E. Stiglitz (2009) Political Economy of Capabilities Accumulation: the Past and Future of Policies for Industrial Development edited by Oxford: Oxford University Press

Easterly, W. and Reshef, A. (2010) African Export Successes: Surprises, Stylized Factsand Explanations. NBER Working Paper No. 16597

FAO (2006) Land Tenure, Food Security and Investment in Postwar Sierra Leone Livelihood Support Programme. Working Paper 22

Government of Sierra Leone (2010) National Export Strategy (NES), June

International Trade Center (2011) Trade and Investment Data. http://www.intracen.org/country/sierra-leone/

Jalloh, A. (2003) Informal credit and politics in Sierra Leone. African Economic History, 31: 91110

Johnson, O.E.G. (2011) Reforming the Customary Land Tenure System in Sierra Leone: A Proposal. IGC Working Paper 11/0558, July 2011.

Ministry of Agriculture, Forestry and Food Security (2010) Smallholders Commercialization Programme. Investment Plan 
Robinson, J.A. (2009) Industrial Policy and Development: A Political Economy Perspective, paper prepared for the 2009 World Bank ABCDE Conference, Seoul, 22-24 June

Spence, M.M. (2003) Evaluating Export Promotion Programmes: UK Overseas Trade Missions and Export Performance. Small Business Economics. 20: 83-103

UNECA (2010) Industrial Policies for the Structural Transformation of African Economies: Options and Best Practices. United Nations Commission for Africa, Addis Ababa, Ethiopia

World Bank (2011) Doing Business. Making a Difference for Entrepreneurs. Comparing Business Regulation in 183 Economies 


\section{The International Growth Centre (IGC) aims to promote sustainable growth in developing countries by providing demand-led policy advice based on frontier research.}

Find out more about

our work on our website

www.theigc.org

For media or communications

enquiries, please contact

mail@theigc.org

Subscribe to our newsletter and topic updates

www.theigc.org/newsletter

Follow us on Twitter

@the_igc

\section{Contact us}

International Growth Centre, London School of Economic and Political Science, Houghton Street,

London WC2A 2AE

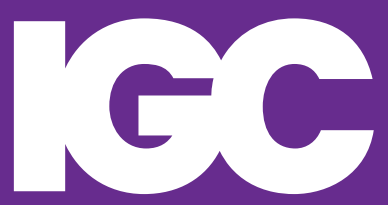

International Growth Centre 